\title{
RESEARCH
}

Open Access

\section{The plasma peptides of sepsis}

\author{
Thanusi Thavarajah1', Claudia C. dos Santos², Arthur S. Slutsky³, John C. Marshall ${ }^{4}$, Pete Bowden',
} Alexander Romaschin ${ }^{2}$ and John G. Marshall ${ }^{1,4^{*}}$ (1)

\begin{abstract}
Background: A practical strategy to discover sepsis specific proteins may be to compare the plasma peptides and proteins from patients in the intensive care unit with and without sepsis. The aim was to discover proteins and/or peptides that show greater observation frequency and/or precursor intensity in sepsis. The endogenous tryptic peptides of ICU-Sepsis were compared to ICU Control, ovarian cancer, breast cancer, female normal, sepsis, heart attack, Alzheimer's and multiple sclerosis along with their institution-matched controls, female normals and normal samples collected directly onto ice.
\end{abstract}

Methods: Endogenous tryptic peptides were extracted from individual sepsis and control EDTA plasma samples in a step gradient of acetonitrile for random and independent sampling by LC-ESI-MS/MS with a set of robust and sensitive linear quadrupole ion traps. The MS/MS spectra were fit to fully tryptic peptides within proteins using the XITANDEM algorithm. The protein observation frequency was counted using the SEQUEST algorithm after selecting the single best charge state and peptide sequence for each MS/MS spectra. The protein observation frequency of ICU-sepsis versus ICU Control was subsequently tested by Chi square analysis. The average protein or peptide $\log _{10}$ precursor intensity was compared across disease and control treatments by ANOVA in the R statistical system.

Results: Peptides and/or phosphopeptides of common plasma proteins such as ITIH3, SAA2, SAA1, and FN1 showed increased observation frequency by Chi square $\left(x^{2}>9, p<0.003\right)$ and/or precursor intensity in sepsis. Cellular gene symbols with large Chi square values from tryptic peptides included POTEB, CTNNA1, U2SURP, KIF24, NLGN2, KSR1, GTF2H1, KIT, RPS6KL1, VAV2, HSPA7, SMC2, TCEB3B, ZNF300, SUPV3L1, ADAMTS20, LAMB4, MCCC1, SUPT6H, SCN9A, SBNO1, EPHA1, ABLIM2, CB5E3.2, EPHA10, GRIN2B, HIVEP2, CCL16, TKT, LRP2 and TMF1 amongst others showed increased observation frequency. Similarly, increased frequency of tryptic phosphopeptides were observed from POM121C, SCN8A, TMED8, NSUN7, SLX4, MADD, DNLZ, PDE3B, UTY, DEPDC7, MTX1, MYO1E, RXRB, SYDE1, FN1, PUS7L, FYCO1, USP26, ACAP2, AHI1, KSR2, LMAN1, ZNF280D and SLC8A2 amongst others. Increases in mean precursor intensity in peptides from common plasma proteins such as ITIH3, SAA2, SAA1, and FN1 as well as cellular proteins such as COL24A1, POTEB, KANK1, SDCBP2, DNAH11, ADAMTS7, MLLT1, TTC21A, TSHR, SLX4, MTCH1, and PUS7L among others were associated with sepsis. The processing of SAA1 included the cleavage of the terminal peptide D/PNHFRPAGLPEKY from the most hydrophilic point of SAA1 on the $\mathrm{COOH}$ side of the cystatin $\mathrm{C}$ binding that was most apparent in ICU-Sepsis patients compared to all other diseases and controls. Additional cleavage of SAA1 on the NH2 terminus side of the cystatin binding site were observed in ICU-Sepsis. Thus there was disease associated variation in the processing of SAA1 in ICU-Sepsis versus ICU controls or other diseases and controls.

\footnotetext{
*Correspondence: 4marshal@ryerson.ca

${ }^{1}$ Ryerson Analytical Biochemistry Laboratory (RABL), Department

of Chemistry and Biology, Faculty of Science, Ryerson University, 350

Victoria St., Toronto, ON, Canada

Full list of author information is available at the end of the article
}

c) The Author(s) 2020. This article is licensed under a Creative Commons Attribution 4.0 International License, which permits use, sharing, adaptation, distribution and reproduction in any medium or format, as long as you give appropriate credit to the original author(s) and the source, provide a link to the Creative Commons licence, and indicate if changes were made. The images or other third party material in this article are included in the article's Creative Commons licence, unless indicated otherwise in a credit line to the material. If material is not included in the article's Creative Commons licence and your intended use is not permitted by statutory regulation or exceeds the permitted use, you will need to obtain permission directly from the copyright holder. To view a copy of this licence, visit http://creativeco mmons.org/licenses/by/4.0/. The Creative Commons Public Domain Dedication waiver (http://creativecommons.org/publicdomain/ zero/1.0/) applies to the data made available in this article, unless otherwise stated in a credit line to the data. 
Conclusion: Specific proteins and peptides that vary between diseases might be discovered by the random and independent sampling of multiple disease and control plasma from different hospital and clinics by LC-ESI-MS/MS for storage in a relational SQL Server database and analysis with the R statistical system that will be a powerful tool for clinical research. The processing of SAA1 may play an unappreciated role in the inflammatory response to Sepsis.

Keywords: Human EDTA plasma, Organic extraction, Nano chromatography, Electrospray ionization tandem mass spectrometry, LC-ESI-MS/MS, Linear quadrupole ion trap, Discovery of variation, Intensive Care Unit, Sepsis, Random and independent sampling, Chi square test and ANOVA, SQL SERVER \& R

\section{Introduction}

\section{Analysis of septic blood by mass spectrometry}

The analysis of septic blood proteins has been recently reviewed, and to date some 198 proteins have been characterized in response to septic infection [1]. Procalcitonin (CALCA) [2] C-reactive protein, interleukin (IL)-6, and soluble urokinase-type plasminogen activator receptor may serve as sepsis markers [1]. The application of 2D electrophoresis of blood fluid together with mass spectral analysis detected increased levels of serum amyloid (SAA1), inter alpha trypsin inhibitor (ITIH3) and APOJ in sepsis [3]. A sepsis model system in mice analyzed using 2D electrophoresis and MALDI-TOF/TOF MS showed changes in $\alpha-1$-antitrypsin, hemopexin, kininogen, $\alpha 1$-acid glycoprotein, apolipoprotein A-1, and complement C3 [4]. Plasma from septic rats showed tubulin alpha $4 \mathrm{~A}$, vinculin, and tropomyosin to be upregulated, while complement components including $\mathrm{C} 3, \mathrm{C} 6$, and $\mathrm{C} 9$ were downregulated [5]. Pentraxin 3 (PTX3) was up regulated in LPS-treated mice and greater levels of oligomerization were associated with improved survival [6]. LPS binding protein (LPB), CRP, serum amyloid A, (SAA) and hepatocyte growth factor-like protein were up regulated in response to LPS injections [7, 8]. Plasma from systemic inflammatory response syndrome versus sepsis patients were compared by LC/LC-ESI-MS/MS that showed increased observation frequency for C4, CRP, plasminogen precursor, apolipoprotein A-II, plasma protease C1 inhibitor precursor, transthyretin precursor, while serum amyloid P-component precursor, apolipoprotein A-I precursor, antithrombin-III precursor, and serum amyloid A-4 protein precursor showed lower observation frequency [8]. The proteins NGAL and VCAM were upregulated in sepsis survivors but downregulated in non-survivors and so may be part of the host response that contributes to survival [9]. Younger adults expressed fibrinogen, and von Willebrand factor in response to sepsis while CRP, LBP, and A1ACT showed lower concentrations in older adults who developed severe sepsis but Apo $\mathrm{M}$ in older adults was associated with increased mortality [10]. IL-1 $\alpha$, IP-10, sTNF-R2, and sFAS could indicate the progression to septic shock while measurement of MMP-3, IL-1 $\alpha$, IP-10, sIL-2R, sFas, sTNF-R1,
sRAGE, GM-CSF, IL-1 $\beta$ and Eotaxin separated survivors [11]. Levels of IL-6, IL-8, and MCP-1 were higher in patients that succumbed to septic shock [12]. A study of 300 septic and non-septic patients showed that the combination of age and gender with CRP and PCT levels could yield a positive diagnosis of sepsis [13]. Cell based markers such as soluble TREM1 and neutrophil CD64 expression showed some utility for sepsis diagnosis [14]. Platelets isolated from patients with severe sepsis or septic shock were compared to healthy donors and showed increased expression, including EFCAB7, actin, IL-1 $\beta$, GPIX, and GPIIB [15]. Recently neutrophil associated Olfactomedin-4 (OLFM4) was indicated to be a potential marker of sepsis [16]. The apparent secretion of proteins such as Defensin alpha-1, myeloperoxidase, resistin, Orosomucoid-1, and Haptoglobin from white blood cells versus CD44 antigen, Granulins, NGAL, Serotransferrin, Catalase, and others may indicate the host response [1, 17]. Here, the selection of septic patients versus a heterogeneous population of ICU patients was employed to look for sepsis markers in the relevant background population $[18,19]$. More recently, the use of two dimensional PAGE revealed that complement components, haptoglobin and ceruloplasmin amongst others show longitudinal variation over the course of septic infection $[20,21]$.

\section{Blood peptides and proteins}

The endogenous peptides of human serum and plasma were first detected by highly sensitive MALDI [22-24]. The MALDI "patterns" formed by the ex vivo degradation of the major peptides of human blood fluids have been compared using complex multivariate approaches [25-29]. However, it is difficult to conceive of how multivariate analysis will function as routine diagnostic [30]. Multivariate "pattern analysis" is prone to over-interpretation of laboratory or clinical experiments and so univariate or two way ANOVA may be a more robust strategy [31-34]. Multivariate analysis provided about the same statistical power compared to the univariate ANOVA of the main feature(s) [32]. The endogenous peptides (peptidome) of human blood were first identified by MS/MS fragmentation using MALDI-Qq-TOF and LC-ESI-MS/ MS with an ion trap mass spectrometer and the intensity 
values compared by ANOVA [32]. The endogenous peptides of blood fluid (peptidome) where no digestion enzyme was specified showed excellent agreement with the exogenously digested tryptic peptides (proteome) [35]. Random and independent sampling of the endogenous tryptic peptides from clinical plasma samples revealed individual peptides or proteins that show significant variation by standard statistical tests such as the Chi square test and ANOVA [32, 36-40]. Pre-analytical variation was exhaustively studied between fresh EDTA plasma samples on ice versus plasma samples degraded for various lengths of time to control for differences in sample handling and storage.

\section{Sample preparation}

The sensitive analysis of blood fluids by LC-ESI-MS/MS is dependent on effective fractionation strategies, such as partition chromatography $[37,41]$ or organic extraction [42-45], to relieve suppression and competition for ionization, resulting in high signal to noise ratios and thus low error rates of identification and quantification [46]. Without step wise sample partition only a few high abundance proteins may be observed from blood fluid $[35,41,42]$. In contrast, with sufficient sample preparation, low abundance proteins of $\leq 1 \mathrm{ng} / \mathrm{ml}$ could be detected and quantified in blood samples by mass spectrometry $[41,44]$. Simple and single-use, i.e. disposable, preparative and analytical separation apparatus permits the identification and quantification of blood peptides and proteins with no possibility of cross contamination between patients that guarantees sampling is statistically independent $[32,35,39,41,44]$. Precipitation and selective extraction of the pellet $[43-45,47]$ was shown to be superior to precipitation and analysis of the $\mathrm{ACN}$ supernatant [48], ultra-filtration, [49] albumin depletion chromatography [50] or C18 partition chromatography alone [35]. Precipitating all of the polypeptides with $90 \%$ ACN followed by step-wise extraction of the peptides with mixtures of organic solvent and water was the optimal method to sensitively detect peptides from blood [42]. Here a step gradient of acetonitrile/water to extract $200 \mu \mathrm{l}$ of EDTA plasma for analysis by LC-ESI-MS/MS showed a high signal to noise ratio [42] and resulted in the confident identification of tryptic peptides [39] from ICU-Sepsis versus ICU Control samples.

\section{Computation and statistics}

Partition of each clinical sample into multiple sub-fractions, that each must be randomly and independently sampled by analytical C18 LC-ESI-MS/MS, provides sensitivity [42] but also creates a large computational challenge. Previously the 32-bit computer power was lacking to identify and compare all the peptides of all the proteins of the many sub-factions from each patient in a large multisite clinical experiment [51]. The MS/ MS spectra from random and independent sampling of peptides from thousands of LC-ESI-MS/MS experiments from multiple clinical treatments and sites may be fit to peptides by the X!TANDEM and SEQUEST algorithms $[52,53]$. The observation frequency and precursor intensity compared across treatments using a 64 bit server SQL SERVER shows excellent data compression and relation for classical analysis with the $\mathrm{R}$ statistical system [36, 39]. The presence of powerful, multi-core 64-bit computation now permits the large scale random and independent sampling of blood peptides and proteins by LC-ESI-MS/MS with followed by peptide correlation and classical analysis in SQL SERVER with the $R$ statistical system. The protein p-values and FDR q-values were computed from organic extraction or chromatography of blood fluid and the peptide-to-protein distribution of the precursor ions of greater than $\sim 10,000$ (E4) counts were compared to a null (i.e. known false positive) model of noise or computer generated random MS/MS spectra [31, 37, 39, 54-56]. Peptides may be identified from the fit of MS/MS spectra to peptide sequences by X!TANDEM [52] that permits the accurate estimate of the type I error rate ( $p$-value) of protein identification that may be corrected by the method Benjamini and Hochberg [57] to yield the FDR (q-value) [39, 42, 54]. Simulations using random or noise MS/MS spectra distributions may be used to control the type I error of experimental MS/MS spectra correlations to tryptic peptides: The peptide and protein observation counts (frequency) may be analyzed using classical statistic methods such as Chi square analysis [55, 58]. A $\log _{10}$ transformation of precursor intensity yields a normal distributions that permits comparison of peptide and proteins expression levels by ANOVA [37, 38]. The SQL Server system permits the direct interrogation of the related data by the open source R statistical system without proteomic-specific software packages. The use of SQL/R has permitted the detailed statistical analysis of randomly and independently sampled LCESI-MS/MS data from multiple hospitals in parallel that would be requisite for a multisite clinical trial $[58,59]$.

\section{ICU-Sepsis versus ICU Control and other disease and controls}

Here, the combination of step wise organic partition [42], random and independent sampling by nano electrospray LC-ESI-MS/MS [39], and 64 bit computation with SQL SERVER/R [36] permitted the sensitive detection of peptides and/or phosphopeptides. Thus, variation in the cleavage of parent protein chains and complexes, from human plasma were compared between ICU-Sepsis versus ICU Control alongside other disease and normal 
plasma by the classical statistical approaches of the Chi square test of observation frequency, STRING analysis of the identified proteins and univariate or two-way ANOVA of protein and peptide intensity [31, 32, 37, 38].

\section{Materials and methods}

\section{Materials}

Anonymous human EDTA plasma with no identifying information were received and analyzed under the Ryerson Ethical Review Board Protocol REB 2015-207: ICU-Sepsis versus ICU Control EDTA plasma were obtained from Clinical Evaluation Research Unit, Kingston General Hospital, Kingston Ontario Canada; Ovarian and breast cancer samples were obtained from the Ontario Tumor bank of the Ontario Institute of Cancer Research, Toronto Ontario; Heart attack (venous and arterial) versus pre-operative orthopedic surgery controls were obtained from St Joseph's Hospital of McMaster University; Multiple sclerosis Alzheimer's dementia and institution-matched normals were obtained from Amsterdam University Medical Centers, Vrije Universiteit Amsterdam; In addition, EDTA plasma samples collected onto ice as a baseline degradation controls were obtained from IBBL Luxembourg [39, 40]. C18 zip tips were obtained from Millipore (Bedford, MA), C18 HPLC resin was from Agilent (Zorbax 300 SB-C18 5-micron). Solvents were obtained from Caledon Laboratories (Georgetown, Ontario, Canada). All other salts and reagents were obtained from Sigma-Aldrich-Fluka (St Louis, MO) except where indicated. The level of replication in the LC-ESI-MS-MS experiments was typically between 9 to 26 independent patient plasma samples (Additional file 1: Table S1).

\section{Sample preparation}

A total of 10 ICU-Sepsis versus 9 ICU Control Human EDTA plasma samples $(200 \mu \mathrm{l})$ were precipitated with 9 volumes of acetonitrile (90\% ACN) [44], followed by extraction of the pellet using a step gradient to achieve selectivity across sub-fractions and thus greater sensitivity [42]. Disposable plastic $2 \mathrm{ml}$ sample tubes and plastic pipette tips were used to handle samples. The acetonitrile suspension was separated with a centrifuge at 12,000 RCF for $5 \mathrm{~min}$. The acetonitrile supernatant, that contains few peptides, was collected, transferred to a fresh sample tube and dried in a rotary lyophilizer. The organic precipitate (pellet) that contains a large total amount of endogenous polypeptides [44] was manually re-suspended using a step gradient of increasing water content to yield 10 fractions from those soluble in $90 \% \mathrm{ACN}$ to $10 \% \mathrm{ACN}$, followed by $100 \% \mathrm{H}_{2} \mathrm{O}$ and then $5 \%$ formic acid [42]. The extracts were clarified with a centrifuge at 12,000 RCF for $5 \mathrm{~min}$. The extracted sample fractions were dried under vacuum in a rotary lyophilizer and stored at $-80{ }^{\circ} \mathrm{C}$ for subsequent analysis.

\section{Preparative C18 chromatography}

Preparative $\mathrm{C} 18$ separation provided the best results for peptides and phosphopeptides analysis in a "blind" test [60]. Solid phase extraction with C18 for LC-ESI-MS/ MS was performed as previously described [32, 35, 41, 44, 47]. The C18 chromatography resin (Zip Tip) was wet with $65 \%$ acetonitrile before equilibration in water with $5 \%$ formic acid. The plasma extract was dissolved in $200 \mu \mathrm{l}$ of $5 \%$ formic acid in water. The resin was washed with at least five volumes of the same binding buffer. The resin was eluted with $\geq 3$ column volumes of $65 \%$ acetonitrile $(2 \mu \mathrm{l})$ in $5 \%$ formic acid. In order to avoid crosscontamination the preparative $\mathrm{C} 18$ resin was discarded after a single use.

\section{LC-ESI-MS/MS}

In order to entirely prevent any possibility of cross contamination, a new disposable nano analytical HPLC column and nano emitter was fabricated for recording each patient sample-fraction set. The ion traps were cleaned and tested for sensitivity with angiotensin and glu fibrinogen prior to recordings. The new column was conditioned and quality controlled with a mixture of three non-human protein standards [31] using a digest of Bovine Cytochrome $\mathrm{C}$, Yeast alcohol dehydrogenase $(\mathrm{ADH})$ and Glycogen Phosphorylase $\mathrm{B}$ to confirm the sensitivity and mass accuracy of the system prior to each patient sample set. The statistical validity of the linear quadrupole ion trap for LC-ESI-MS/MS of human plasma [42] was in agreement with the results from the 3D Paul ion trap [31, 37, 55, 56]. The stepwise extractions were collected and desalted over C18 preparative micro columns, eluted in $2 \mu \mathrm{l}$ of $65 \% \mathrm{ACN}$ and $5 \%$ formic acid, diluted ten-fold with $5 \%$ formic acid in water and $5 \% \mathrm{ACN}$, and immediately loaded manually into a $20 \mu \mathrm{l}$ metal sample loop before injecting onto the analytical column via a Rheodyne injector. Endogenous peptide samples were analyzed over a discontinuous gradient generated at a flow rate of 10 micro litres per minute with an Agilent 1100 series capillary pump and split upstream of the injector during recording to about $200 \mathrm{nl}$ per minute. The separation was performed with a C18 $(150 \mathrm{~mm} \times 0.15 \mathrm{~mm})$ fritted capillary column. The acetonitrile profile was started at $5 \%$, ramped to $12 \%$ after $5 \mathrm{~min}$ and then increased to $65 \%$ over $\sim 90 \mathrm{~min}$, remained at $65 \%$ for $5 \mathrm{~min}$, decreased to $50 \%$ for $15 \mathrm{~min}$ and then declined to a final proportion of $5 \%$ prior to injection of the next step fraction from the same patient. The nano HPLC effluent was analyzed by ESI ionization with detection by MS and fragmentation by MS/MS with 
a linear quadrupole ion trap [61]. The instrument was set to collect the precursors for up to 200 milli seconds prior to MS/MS fragmentation with up to four independent MS/MS fragmentations per precursor ion. Individual, independent samples from disease, normal and ice cold control were precipitated, fractionated over a step gradient and collected over C18 for manual injection.

\section{Correlation analysis}

Correlation analysis of ion trap data was performed using a goodness of fit test by X!TANDEM [52] and by crosscorrelation using SEQUEST [62] on separate servers to match tandem mass spectra to peptide sequences from the Homo sapiens RefSeq, Ensembl, SwissProt, including hypothetical proteins XP or Genomic loci [35, 36, 63]. Endogenous peptides with precursors greater than 10,000 (E4) arbitrary counts were searched only as fully tryptic peptides and/or phosphopeptides, the results were combined, and compared in SQL Server/R. The X!TANDEM default ion trap data settings of $\pm 3 \mathrm{~m} / \mathrm{z}$ from precursor peptides considered from 300 to $2000 \mathrm{~m} / \mathrm{z}$ with a tolerance of $0.5 \mathrm{Da}$ error in the fragments were used [37, 41, $52,55,56,64]$. The best fit peptide of the MS/MS spectra to fully tryptic and/or phospho-tryptic peptides at charge states of +2 versus +3 were accepted with additional acetylation, or oxidation of methionine and with possible loss of water or ammonia. The resulting accession numbers, actual and estimated masses, correlated peptide sequences, peptide intensity and protein scores, resulting protein sequences and other associated data were captured and assembled together in an SQL Server relational database [36].

\section{Data sampling, sorting, transformation and visualization}

The linear quadrupole ion trap provided the precursor ion intensity and $\mathrm{m} / \mathrm{z}$ values plus the peptide fragment MS/MS spectra. The peptides and proteins were identified from MS/MS spectra by X!TANDEM and were counted by the SEQUEST algorithm. The large number of redundant correlations to each MS/MS at different charge states or to different sequences may be a source of type I error that may be filtered out by a complex key in SQL Server. The MS and MS/MS spectra together with the results of the X!TANDEM and SEQUEST algorithms were parsed into an SQL Server database and filtered [36] before statistical and graphical analysis with the generic $\mathrm{R}$ data system [31, 36-38, 63]. The peptide to protein correlation frequency counts for each gene symbol were summed over sepsis versus the matched control to correct the observation frequency for the Chi square test using Eq. 1:

$$
(\text { ICU_Sepsis - ICU_Control })^{2} /(\text { ICU_Control + 1) }
$$

The precursor intensity data for MS/MS spectra were $\log _{10}$ transformed, tested for normality and analyzed across institution/study and diseases verses controls by means, standard errors and ANOVA [31, 37, 38]. The entirely independent analysis of the precursor intensity using the rigorous ANOVA with Tukey-Kramer HSD test versus multiple controls was achieved using a 64-bit R server.

\section{Results}

Partition of plasma samples using differential solubility in organic/water mixtures combined with random and independent sampling by LC-ESI-MS/MS detected peptides and proteins that were more frequently observed and/or showed greater intensity in ICU-Sepsis versus ICU Control. Here four independent lines of evidence, Chi square analysis of observation frequency, previously established structural/functional relationships from STRING, ANOVA analysis of peptide intensity, and agreement with the previous genetic or biochemical experiments, all indicated that there was significant variation in the peptides of ICU-Sepsis patients compared to ICU Control and other diseases or normal plasma samples.

\section{LC-ESI-MS/MS}

The pool of endogenous tryptic (TRYP) and/or tryptic phosphopeptides (TRYP STYP) were randomly and independently sampled without replacement by liquid chromatography, nano electrospray ionization and tandem mass spectrometry (LC-ESI-MS/MS) [39] from ICUSepsis vs ICU Control, other disease and normal plasma, and ice cold controls to serve as a baseline [40, 65]. Some $15,968,550 \mathrm{MS} / \mathrm{MS}$ spectra $\geq \mathrm{E} 4$ intensity counts were correlated by the SEQUEST and X!TANDEM algorithms that resulted in a total of 19,197,152 redundant matches of MS/MS spectra to peptides in proteins. The redundant correlations from SEQUEST were filtered to retain only the best fit by charge state and peptide sequence in SQL Server to avoid re-use of the same MS/MS spectra. The filtered results were then analyzed by the generic $R$ statistical system in a matrix of disease and controls that reveals the set of blood peptides and proteins specific to each disease state. The statistical validity of the extraction and sampling system were previously established by computation of protein gene symbols $p$-values and FDR corrected q-values by the method of Benjamini and Hochberg [57] and frequency comparison to false positive noise or random spectra $[39,42]$. 


\section{Frequency correction}

Chi square $\left(\chi^{2}\right)$ may be used to compare discrete, "counting" variables such as observation frequency. A total of 486,367 MS/MS $\geq$ E4 counts were collected from ICUSepsis samples and 424,591 MS/MS $\geq E 4$ counts were collected from ICU Control plasma and these sums were used to correct observation frequency. Similar results were obtained from comparison corrected on the basis of total correlations (not shown). Many proteins show large increases or decreases in observation frequency between ICU Sepsis versus the matched ICU Control resulting in large Chi square values (Fig. 1).

\section{Comparison of sepsis to matched control by Chi square analysis}

A set of $\sim 50$ gene symbols showed a substantial difference $\geq 9$ counts and a Chi square $\left(x^{2}\right)$ values of $\geq 9$ between ICU-Sepsis versus the matched ICU Control. For $\chi^{2}$ analysis the tryptic peptides (TRYP) were computed independently from the phospho-tryptic peptides. Specific peptides and/or phosphopeptides from cellular proteins, membrane proteins, nucleic acid binding proteins, signaling factors, metabolic enzymes and others including uncharacterized proteins showed significantly greater observation frequency in ICU-Sepsis. In agreement with the literature, peptides from ITIH3, SAA2,
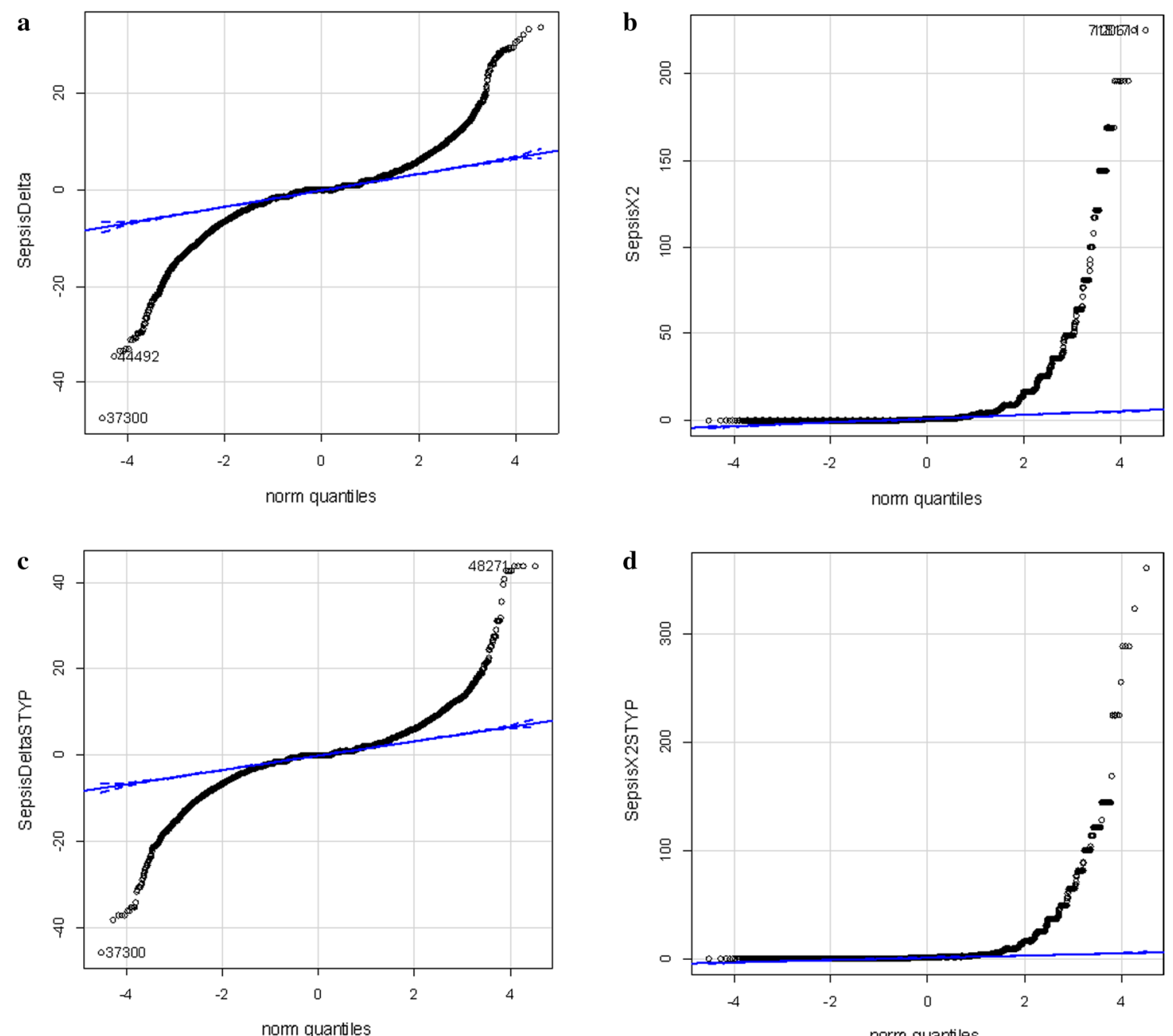

Fig. 1 Quantile plots of the corrected difference in observation frequency and Chi square values of the ICU-Sepsis $(n \geq 10)$ versus ICU Control $(n \geq 9)$. a Quantile plot of the observation frequency of tryptic peptides from ICU-Sepsis versus ICU Control. $\mathbf{b} x^{2}$ plot of the observation frequency of tryptic peptides from ICU-Sepsis versus ICU Control cancer tryptic peptides. c Quantile plot of the observation frequency of tryptic STYP peptides from ICU-Sepsis versus ICU Control. d X $x^{2}$ plot of the observation frequency of tryptic STYP peptides from ICU-Sepsis versus ICU Control tryptic peptides 
SAA1, and FN1 showed variation in observation frequency between ICU-Sepsis versus ICU Control. The Chi square analysis showed some cellular proteins with large changes in frequency by Chi square $\left(X^{2}>9, p \leq 0.00389\right)$ from tryptic (TYRP) peptides such as POTEB, CTNNA1, U2SURP, KIF24, NLGN2, KSR1, GTF2H1, KIT, RPS6KL1, VAV2, HSPA7, SMC2, TCEB3B, ZNF300, SUPV3L1, ADAMTS20, LAMB4, MCCC1, SUPT6H, SCN9A, SBNO1, EPHA1, ABLIM2, cB5E3.2, EPHA10, GRIN2B, HIVEP2, CCL16, TKT, LRP2 and TMF1 amongst others. Similarly, increased tryptic phosphopeptides were observed from POM121C, SCN8A, TMED8, NSUN7, SLX4, MADD, DNLZ, PDE3B, UTY, DEPDC7, MTX1, MYO1E, RXRB, SYDE1, FN1, PUS7L, FYCO1, USP26, ACAP2, AHI1, KSR2, LMAN1, ZNF280D and SLC8A2 amongst others (Table 1). Observation frequency may be the best measure of relative abundance [66] and the full list of Chi square results are found in Additional files 1, 2, 3 that is the most important result of this study.

Table 1 Sepsis specific proteins detected by fully tryptic peptides and/or fully tryptic phosphopeptides that show a Chi square $\left(x^{2}\right)$ value of $\geq 45$

\begin{tabular}{|c|c|c|c|c|c|}
\hline TRYP_gene_symbol & Sepsis_X2 & Gene_symbol_n & STYP_gene_symbol & STYP_X2 & $\begin{array}{l}\text { Gene_- } \\
\text { symbol_n }\end{array}$ \\
\hline POTEB & 210.5 & 2 & POM121C & 324.0 & 1 \\
\hline POTEB2 & 196.0 & 1 & SCN8A & 273.0 & 4 \\
\hline CTNNA1 & 178.7 & 3 & TMED8 & 156.5 & 2 \\
\hline U2SURP & 178.0 & 3 & NSUN7 & 132.5 & 2 \\
\hline KIF24 & 146.9 & 4 & SLX4 & 127.9 & 1 \\
\hline NLGN2 & 144.0 & 2 & MADD & 121.1 & 26 \\
\hline $\mathrm{ITIH} 3$ & 139.4 & 5 & DNLZ & 121.0 & 1 \\
\hline KSR1 & 132.9 & 8 & PDE3B & 107.0 & 3 \\
\hline GTF2H1 & 121.0 & 2 & UTY & 105.6 & 57 \\
\hline KIT & 121.0 & 1 & SAA2 & 103.1 & 1 \\
\hline RPS6KL1 & 114.5 & 7 & DEPDC7 & 100.0 & 2 \\
\hline VAV2 & 111.8 & 4 & MTX1 & 100.0 & 1 \\
\hline HSPA7 & 100.0 & 1 & MYO1E & 100.0 & 1 \\
\hline SMC2 & 100.0 & 1 & RXRB & 90.5 & 6 \\
\hline TCEB3B & 100.0 & 1 & SYDE1 & 84.2 & 4 \\
\hline ZNF300 & 100.0 & 1 & SAA1 & 71.0 & 4 \\
\hline SUPV3L1 & 83.8 & 2 & FN1 & 67.5 & 28 \\
\hline ADAMTS20 & 76.6 & 2 & PUS7L & 64.2 & 3 \\
\hline LAMB4 & 76.6 & 2 & FYCO1 & 63.6 & 3 \\
\hline SAA2 & 71.5 & 1 & USP26 & 59.8 & 2 \\
\hline SAA1 & 71.1 & 4 & ACAP2 & 55.5 & 3 \\
\hline MCCC1 & 69.1 & 2 & $\mathrm{AHI} 1$ & 55.5 & 1 \\
\hline SUPT6H & 65.3 & 2 & DKFZp686012165 & 55.5 & 1 \\
\hline SCN9A & 61.5 & 4 & KSR2 & 55.5 & 3 \\
\hline SBNO1 & 60.3 & 2 & LMAN1 & 55.5 & 1 \\
\hline EPHA1 & 57.5 & 3 & ZNF280D & 55.2 & 9 \\
\hline ABLIM2 & 55.7 & 2 & SLC8A2 & 50.9 & 2 \\
\hline CB5E3.2 & 55.7 & 1 & ITPR2 & 49.8 & 2 \\
\hline EPHA10 & 55.7 & 2 & GPHN & 49.8 & 8 \\
\hline GRIN2B & 55.7 & 1 & HES6 & 48.6 & 1 \\
\hline HIVEP2 & 54.4 & 1 & OSBPL7 & 48.6 & 3 \\
\hline CCL16 & 53.8 & 1 & TRPM6 & 47.2 & 8 \\
\hline TKT & 52.4 & 4 & MSR1 & 46.7 & 5 \\
\hline LRP2 & 52.3 & 2 & C17orf25 & 46.3 & 1 \\
\hline TMF1 & 51.9 & 2 & GPHRYN & 46.3 & 1 \\
\hline
\end{tabular}

The full set of gene symbols from tryptic and phospho tryptic peptides and the resulting STRING analysis may be found in Additional files 1, 2, 3: Tables S1, S2 and S3 


\section{STRING network analysis}

Taking the Gene symbols that varied between ICUSepsis versus ICU Control by Chi square $\left(x^{2}\right)$ revealed a network of proteins that show a dense and complex set of interconnections with 484 nodes connected by 1147 edges with a PPI enrichment $\mathrm{p}$-value of $<1.0 \mathrm{e}-16$ (see Additional file 1: Table S1). The analysis of the proteins with high observation frequencies showed proteins associated with phagocytic functions such as actin-mysoin and tubulin- dynein cytoskeleton and supramolecular fiber networks, motility, contractile proteins and proteins associated with fila podia or cell projections, the release of membrane bound organelle, lumen contents, and ATP/GTP binding and hydrolysis proteins involved in metabolic energy or cellular regulation (see Additional files 1, 2, 3). For the purposes of illustration the proteins that showed at least 9 greater observations (Delta) and $\chi^{2}$ values greater than $9(\mathrm{p} \leq 0.003)$ are shown separate as tryptic (TRYP) versus tryptic or phospho-tryptic peptides (STYP) (Fig. 2 and 3). The full list of Gene Symbols from tryptic peptides, phospho tryptic peptides and the resulting STRING analysis may be found in Additional files 1, 2, 3: Table S1, S2 and S3.

\section{Quantile box plots and ANOVA analysis across disease and control treatments}

ANOVA may be an independent method to confirm the potential utility of peptides from Gene symbols that

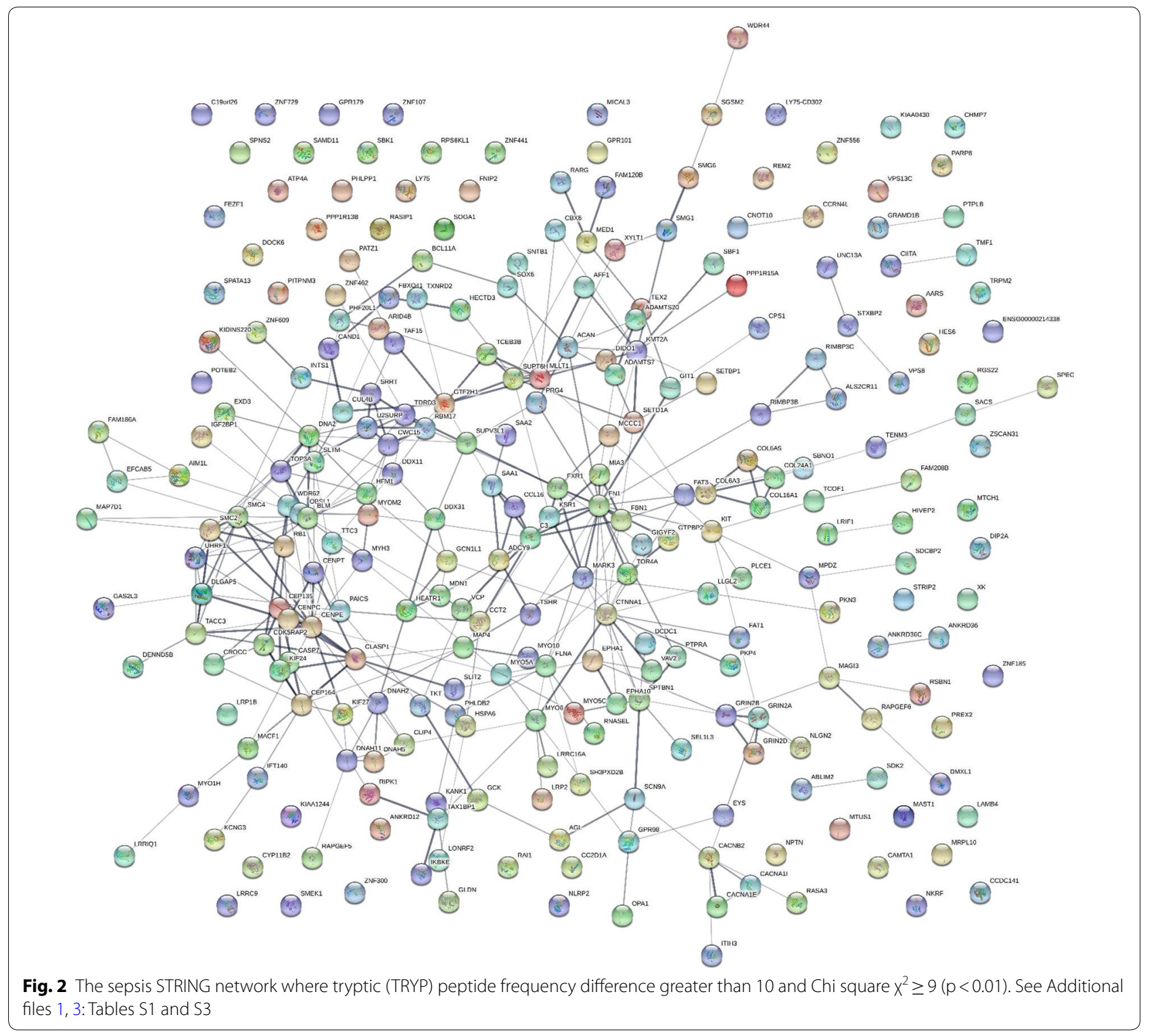




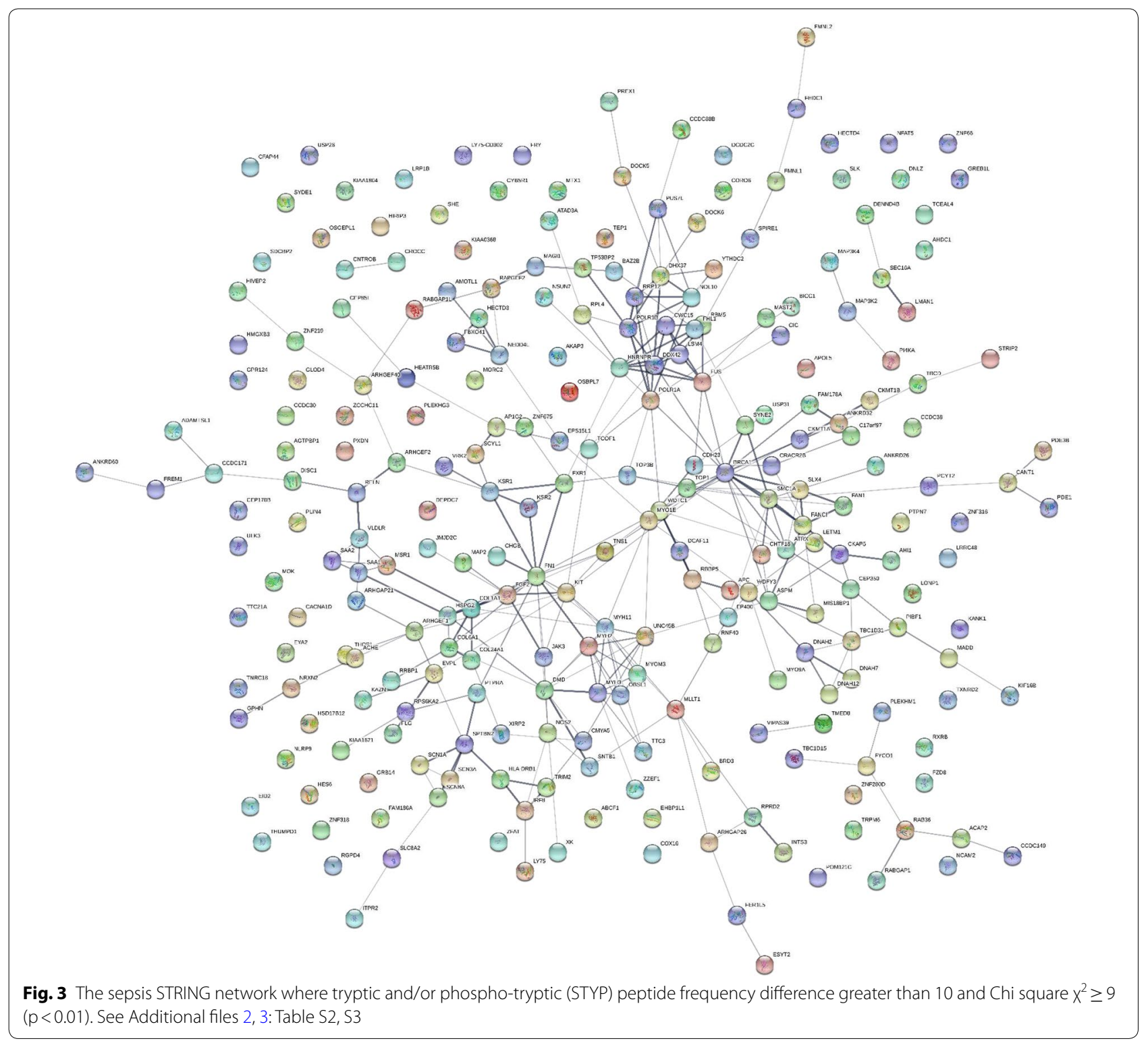

showed increased observation frequency by Chi square. Some proteins that showed greater observation frequency in sepsis also showed significant variation in protein or peptide precursor intensity compared to the sepsis controls and/or other disease and normal EDTA plasma by quantile box plots and/or ANOVA comparison. The mean precursor intensity values from gene symbols that varied by Chi square $\left(\chi^{2}>9\right)$ from tryptic and/ or phospho tryptic were subsequently analyzed by univariate ANOVA in $\mathrm{R}$ to look for proteins that showed significant variation in precursor intensity values across treatments [32, 38] (Figs. 4 and 5). Common plasma proteins including ITIH3, FN1 and SAA1 showed significant variation in average peptide $\log _{10}$ intensity across treatments (Fig. 4). Analysis of the precursor intensity by quantile box plots and ANOVA confirmed significant variation in cellular proteins with increased observation frequency in sepsis such as COL24A1, POTEB, KANK1, SDCBP2, DNAH11, ADAMTS7, MLLT1, TTC21A, TSHR, SLX4, MTCH1, and PUS7L (Fig. 5).

Processing of SAA 1 in sepsis versus matched controls The SAA1 protein that best fit the MS/MS spectra observed from human plasma was accession 
AAH07022.1. The observation frequency of peptides from SAA1 was much higher in ICU-Sepsis compared to any other disease of control treatment (Table 2). The processing of SAA1 including the cleavage of the C-terminal tryptic peptide DPNHFRPAGLPEKY from the most hydrophilic point of SAA1 on the $\mathrm{COOH}$ side of the Cystatin $\mathrm{C}$ binding was most apparent in ICU-Sepsis patients compared to all other diseases and controls. Additional cleavages of SAA1 on the $\mathrm{NH} 2$ terminus side of the Cystatin Binding Site were observed in ICU-Sepsis. An exopeptidase activity apparently removed the N-terminal aspartic acid, D, from some of the released peptides that we represent as D/PNHFRPAGLPEKY. Thus there was disease associated variation in the processing of SAA1 in ICU-Sepsis versus ICU controls or other diseases and normal (Table 2). The cleavage of the terminal peptide D/PNHFRPAGLPEKY from the most hydrophilic point of SAA1 on the $\mathrm{COOH}$ side of the cystatin binding site (Figs. 6 and 7) was most frequently observed in ICU-Sepsis compared to all other treatments. Septic patients showed the cleavage of ${ }_{109} \mathrm{D} / \mathrm{PNHFRPAGL}-$ $\mathrm{PEKY}_{122}$ from the $\mathrm{COOH}$ terminus plus additional cleavages on the $\mathrm{NH} 2$ side of the Cystatin $\mathrm{C}$ binding site of SAA1 at the tryptic cleavage site ${ }_{20}$ SFFSFLGEAFDGAR $_{33}$, ${ }_{53}$ YFHARGNYDAAK $_{64}$ and the peptide ${ }_{86}$ FFGHGAEDSLADQAADEWGR ${ }_{105}$ that overlaps the cystatin binding site (Figs. 6 and 7). Thus, the processing of SAA1 in ICUSepsis patients apparently varied compared to all other diseases and controls.

\section{Discussion}

A simple and direct strategy to discover variation in peptides or proteins specific to ICU-Sepsis may be to compare them to ICU control, alongside other disease and normals under identical conditions. The aim and objective of this study was proof of concept towards a method to compare the endogenous tryptic peptides of ICU-Sepsis to those from ICU Control and other disease or normals by random and independent sampling with a set of robust and sensitive linear quadrupole ion traps where the results were collected in an SQL Server for analysis with the $\mathrm{R}$ statistical system. Random and independent sampling of peptides from step-wise fractionation followed by LC-ESI-MS/MS is a time and manual labor intensive approach that is sensitive, direct, and rests on few assumptions $[39,67]$. High signal to noise ratio of blood peptides is dependent on sample preparation to break the sample into many sub-fractions to relieve competition and suppression of ionization and thus achieve sensitivity [35, 41, 42] but then requires large computing power to re-assemble the sub-fractions, back into individual patient samples within treatments [36, 42, 67]. The approach shows great sensitivity and flexibility but relies on the fit of MS/MS spectra by X!TANDEM and SEQUEST $[52,53]$ to assign peptide identity and statistical analysis of precursor ion counts and intensity by Chi square and ANOVA and so is computationally intensive $[31,36]$. The careful study of variation over time, and under various storage and preservation conditions, seems to rule out pre-clinical variation as the most important source of variation between ICU-Sepsis versus ICU Control or other disease and control treatments [39, 40, 65].

\section{Discovery by Chi square $\left(\mathrm{x}^{2}\right)$ analysis of observation frequency}

The SQL Server and R statistical system permits the rapid statistical and graphical analysis of the data at the level of Gene symbols, proteins or peptides. The Chi square $\left(x^{2}\right)$ algorithm is simple means to compute the differences in observation frequency that can be extensively applied to all gene symbols to reveal peptides and proteins that apparently differ between two treatments. Examining the observation frequency by Chi square between ICUSepsis versus ICU Control revealed a large set of proteins that not been previously discovered with respect to sepsis in the literature. Analysis of the protein and peptides frequently observed in sepsis across all twelve disease and controls clinical sample sets using box plots and ANOVA was a direct means to look for factors specific to sepsis that might play a role in the host response to septic infection that have not been previously considered in the literature.

\section{STRING analysis}

The large number of edge connections between the gene symbols with increased observation frequency in sepsis indicates the proteins observed show biological and protein- interactions and were not a random assemblage

\footnotetext{
(See figure on next page.)

Fig. 4 The distributions of $\log _{10}$ precursor intensity by quantile and box plots of serum proteins APOE, ITIH4, and C 3 across the disease and control treatments. Treatment ID numbers: 1, Alzheimer normal; 2, Alzheimer's normal control STYP; 3, Alzheimer's dementia; 4, Alzheimer's dementia STYP; 5, Cancer breast; 6, Cancer breast STYP; 7, Cancer control; 8, Cancer control STYP; 9, Cancer ovarian; 10, Cancer ovarian STYP; 11, Ice Cold; 12, Ice Cold STYP; 13, Heart attack Arterial; 14 Heart attack Arterial STYP; 15, Heart attack normal control, 16, Heart attack normal Control STYP; 17, Heart attack; 18, Heart attack STYP; 19, Multiple Sclerosis normal control; 20, Multiple sclerosis normal control STYP; 21, Multiple sclerosis; 22, Multiple Sclerosis STYP, 23, Sepsis; 24, Sepsis STYP; 25, Sepsis normal control; 26, Sepsis normal control STYP. There was significant effects of treatments and peptides by two-way ANOVA. Analysis of the proteins shown across treatments produced a significant F Statistic by one-way ANOVA
} 

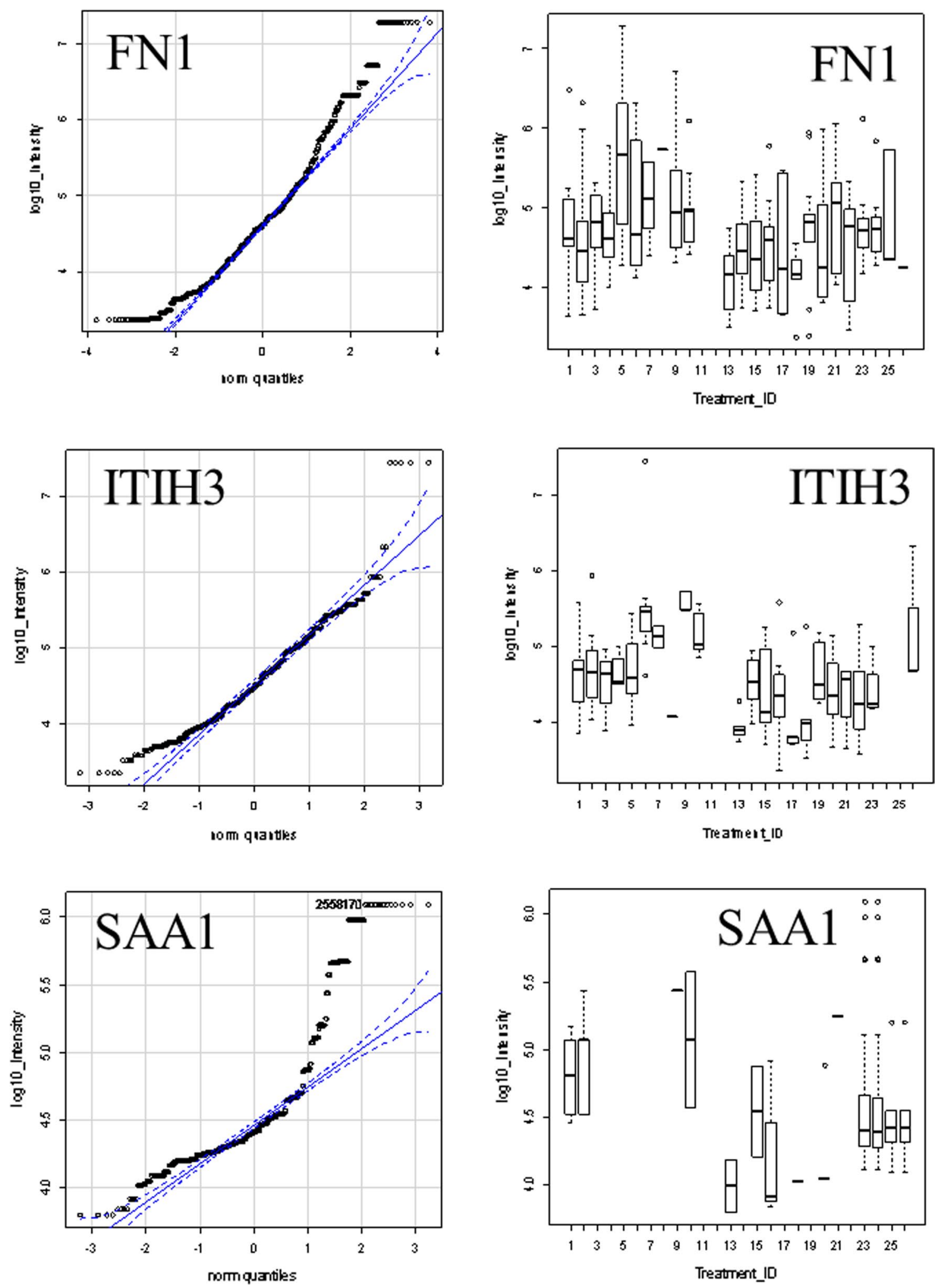


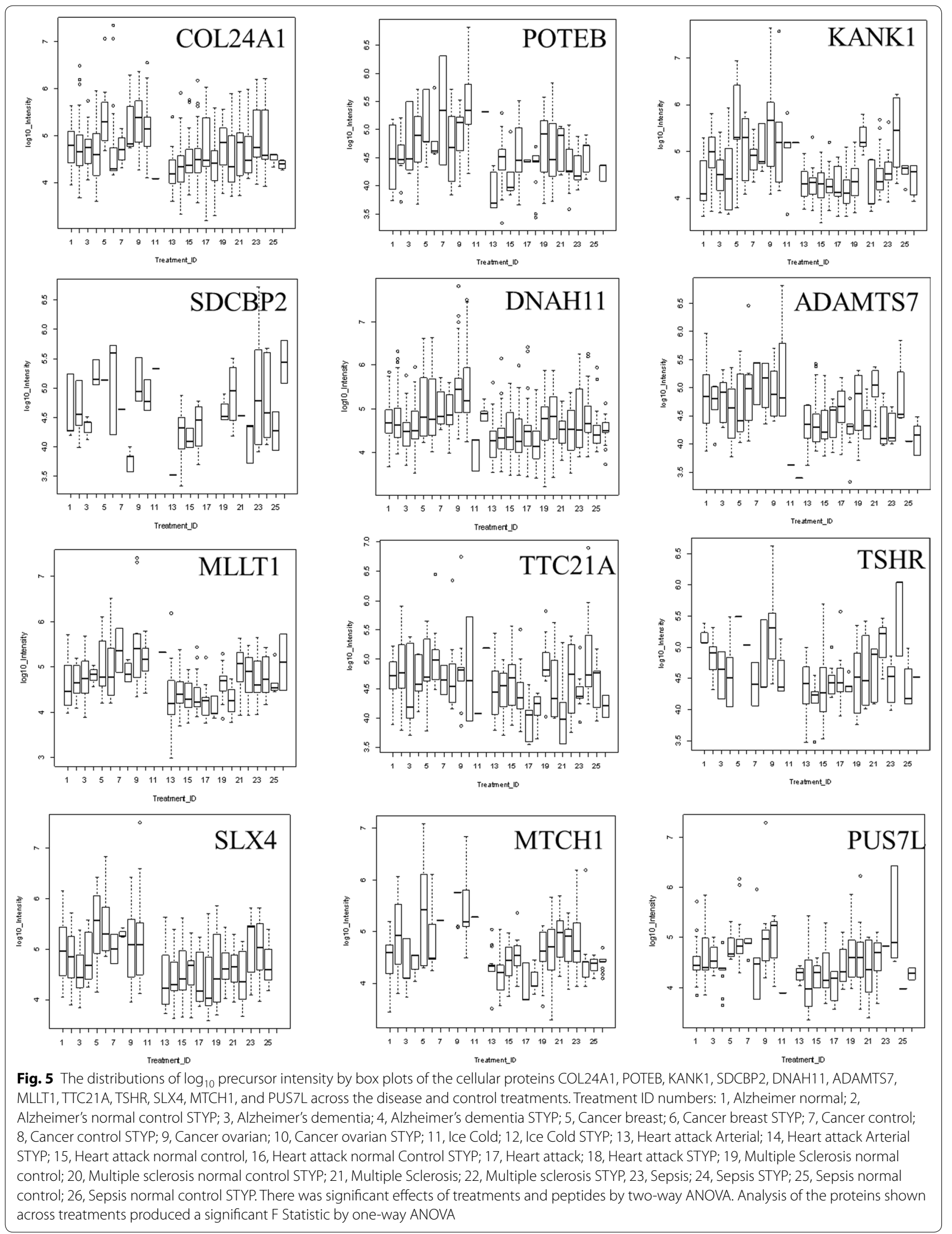


Table 2 The analysis of redundant mean peptide intensity and observation frequency of the full length and truncated SAA1 protein

\begin{tabular}{|c|c|c|c|c|c|c|}
\hline \multirow[t]{2}{*}{ Treatment_ID } & \multicolumn{3}{|l|}{ Full length SAA1 } & \multicolumn{3}{|l|}{ Truncated SAA1 } \\
\hline & Peptide_intensity & se (mean) & Data: n & Peptide_intensity & se (mean) & Data: $\mathbf{n}$ \\
\hline 1 & $104,227.4$ & $32,319.6$ & 7 & $104,227.4$ & $32,319.6$ & 7 \\
\hline 2 & $89,372.6$ & $50,226.2$ & 5 & $89,372.6$ & $50,226.2$ & 5 \\
\hline 4 & $20,655.1$ & $11,064.5$ & 2 & $20,655.1$ & $11,064.5$ & 2 \\
\hline 5 & $2,918,290.3$ & NA & 1 & $2,918,290.3$ & NA & 1 \\
\hline 6 & $426,255.1$ & NA & 1 & $426,255.1$ & NA & 1 \\
\hline 9 & $174,935.2$ & $100,095.9$ & 2 & $174,935.2$ & $100,095.9$ & 2 \\
\hline 10 & $335,900.6$ & $209,560.4$ & 4 & $335,900.6$ & $209,560.4$ & 4 \\
\hline 13 & $19,326.3$ & $11,375.7$ & 4 & $19,326.3$ & $11,375.7$ & 4 \\
\hline 15 & $31,441.6$ & 8916.8 & 9 & $31,441.6$ & 8916.8 & 9 \\
\hline 16 & $18,908.6$ & 7187.1 & 10 & $18,908.6$ & 7187.1 & 10 \\
\hline 17 & $20,049.3$ & 8467.0 & 3 & $20,049.3$ & 8467.0 & 3 \\
\hline 18 & $138,654.0$ & $120,611.1$ & 4 & $138,654.0$ & $120,611.1$ & 4 \\
\hline 19 & $34,821.0$ & NA & 1 & $34,821.0$ & NA & 1 \\
\hline 20 & $140,968.2$ & $112,007.7$ & 5 & $140,968.2$ & $112,007.7$ & 5 \\
\hline 21 & $178,542.8$ & NA & 1 & $178,542.8$ & NA & 1 \\
\hline 22 & $11,157.6$ & NA & 1 & $11,157.6$ & NA & 1 \\
\hline 23 & $109,959.2$ & $28,031.2$ & 80 & $55,875.9$ & $13,232.7$ & 21 \\
\hline 24 & $106,006.4$ & $28,315.5$ & 79 & $37,558.3$ & 3945.8 & 20 \\
\hline 25 & $43,369.7$ & 9799.9 & 19 & $46,682.4$ & 8607.8 & 4 \\
\hline 26 & $42,592.9$ & $10,314.1$ & 18 & $43,126.0$ & $10,418.8$ & 3 \\
\hline
\end{tabular}

Treatment ID numbers: 1, Alzheimer normal; 2, Alzheimer's normal control STYP; 3, Alzheimer's dementia; 4, Alzheimer's dementia STYP; 5, Cancer breast; 6, Cancer breast STYP; 7, Cancer control; 8, Cancer control STYP; 9, Cancer ovarian; 10, Cancer ovarian STYP; 11, Ice Cold; 12, Ice Cold STYP; 13, Heart attack Arterial; 14, Heart attack Arterial STYP; 15, Heart attack normal control, 16, Heart attack normal Control STYP; 17, Heart attack; 18, Heart attack STYP; 19, Multiple Sclerosis normal control; 20, Multiple sclerosis normal control STYP; 21, Multiple sclerosis; 22, Multiple Sclerosis STYP, 23, Sepsis; 24, Sepsis STYP; 25, Sepsis normal control; 26, Sepsis normal control STYP

of factors consistent with bone fide biological variation between the ICU-Sepsis versus ICU Control treatments. The network analysis showed proteins associated with cell motility and contraction, formation of cellular extensions, secretion of the lumen contents of membrane bound organelles expected in inflammation and the host response to bacteria that indicated a role for the innate immune response of leukocytes $[9,12,20,21]$ and was consistent with regulation of leukocytes by cytokines, chemokines and other potent regulatory factors (see Additional file 1: Table S1) [10].

\section{ICU-Sepsis versus ICU Control alongside other diseases and control by ANOVA}

Proteins that showed increased observation frequency in ICU-Sepsis versus ICU Control by Chi square $\left(x^{2}\right)$ were then analyzed across all disease and controls treatments by box plots, quantile plots and ANOVA. The analysis of mean precursor intensity $[32,37,38]$ is complicated by the different peptide sequences within each protein that required two way ANOVA [31] and peptides shared by different proteins, or tryptic versus phospho-tryptic peptides that confound simplistic analysis. While the

\footnotetext{
(See figure on next page.)

Fig. 6 SAA1 peptides including the COOH terminal PNHFRPAGLPEKY peptide versus all other more NH2 terminal peptides. a D/PNHFRPAGLPEKY quantile plot. b D/PNHFRPAGLPEKY intensity box plot. c SAA1 amino terminal peptide FFGHGAEDSLADQAANEWG quantile plot. d SAA1 amino terminal peptide FFGHGAEDSLADQAANEWG box plot. e SAA1 amino terminal grouped peptide FFGHGAEDSLADQAANEWG, RSFFSFLGEAFDGAR \& YFHARGNYDAAKR quantile plot. f SAA1 amino terminal grouped peptide FFGHGAEDSLADQAANEWG, RSFFSFLGEAFDGAR and YFHARGNYDAAKR box plot. Treatment ID numbers: 1, Alzheimer normal; 2, Alzheimer's normal control STYP; 3, Alzheimer's dementia; 4, Alzheimer's dementia STYP; 5, Cancer breast; 6, Cancer breast STYP; 7, Cancer control; 8, Cancer control STYP; 9, Cancer ovarian; 10, Cancer ovarian STYP; 11, Ice Cold; 12, Ice Cold STYP; 13, Heart attack Arterial; 14, Heart attack Arterial STYP; 15, Heart attack normal control, 16, Heart attack normal Control STYP; 17, Heart attack; 18, Heart attack STYP; 19, Multiple Sclerosis normal control; 20, Multiple Sclerosis normal control STYP; 21, Multiple sclerosis; 22, Multiple sclerosis STYP, 23, Sepsis; 24, Sepsis STYP; 25, Sepsis normal control; 26, Sepsis normal control STYP. There was significant effects of treatments and peptides by two-way ANOVA
} 

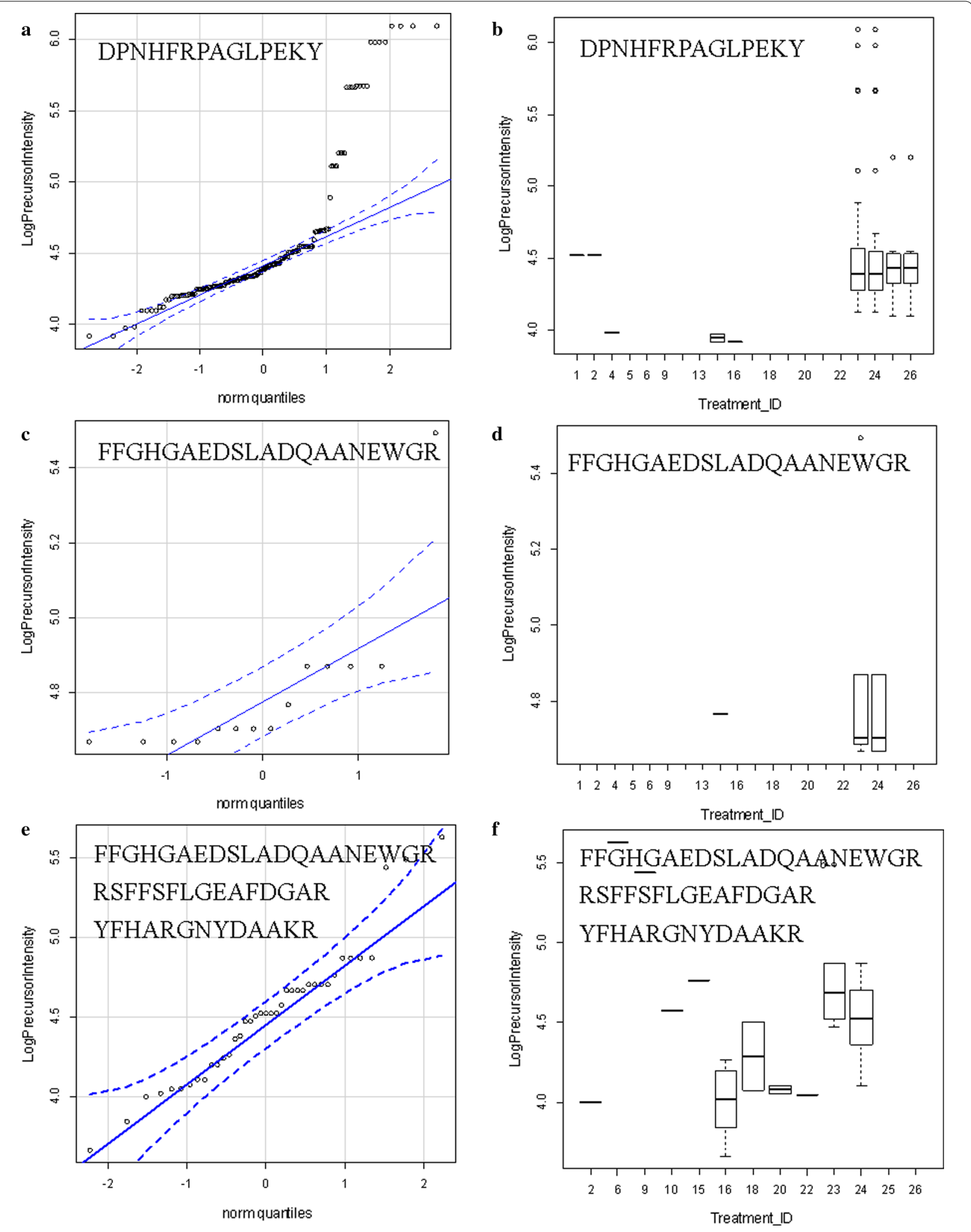

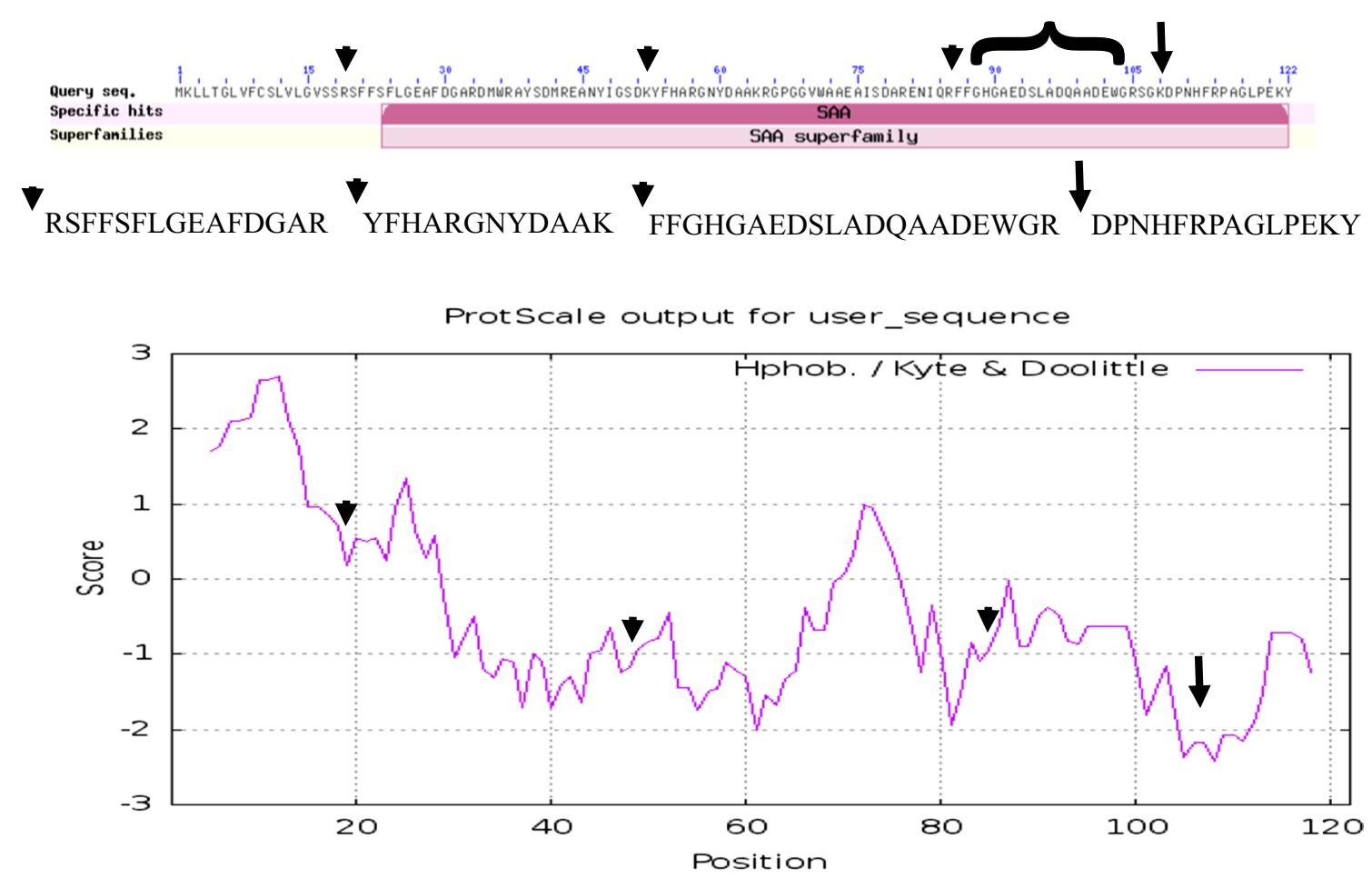

Fig. 7 The primary structure and hydrophilicity plot of SAA1 protein accession AAH07022.1. The long arrow shows the cleavage site of the fully tryptic peptides sequence DPNHFRPAGLPEKY on the $\mathrm{COOH}$ terminus adjacent to the cystatin C binding site from AA 86-104 (bracket) that resolved ICU and Sepsis-ICU from all other treatments and controls. The short arrows show the location of cleavages NH2 terminal of the cystatin $\mathrm{C}$ binding site

simplest model of tryptic peptide identity has been well grounded with respect to random expectation, the more complex assumptions associated with phosphopeptides remain to be examined alongside random spectra [31, $38,54-56$ ] and so are more speculative [64]. Examining the gene symbol intensity across all twelve disease and controls clinical sample sets by box plots and twoway ANOVA was a direct means to compare across all other diseases and controls to look for proteins specific to ICU-Sepsis. Many of the proteins that show increased observation in ICU-Sepsis independently showed greater $\log _{10}$ intensity values that was consistent with true-positive variation between ICU-Sepsis and ICU Control. The FN1, ITIH3, SAA1 and other peptides observed were consistent with previous claims of utility for these proteins as sepsis biomarkers $[68,69]$. Ultimately, analysis of peptides across all treatments will be required to extract all of the information from such as large dataset and will require large and automated computations.

\section{Agreement with previous genetic and biochemical experiments}

SAA1 has been implicated in many different diseases including sepsis [1] and the intact full length protein is unlikely to serve as a specific biomarker [58]. Tryptic peptides cleaved in plasma from SAA1 showed a higher observation frequency and/or mean $\log _{10}$ intensity in sepsis. The SAA1 tryptic peptide D/PNHFRPAGLPEKY, was cleaved from the $\mathrm{COOH}$ terminus of SAA1 and was specific to ICU and ICU-Sepsis patients similar to that observed in patients with the auto inflammatory disorder Kawasaki's disease [70]. The location of the most frequent SAA1 cleavage site $\mathrm{COOH}$ terminal of lysine (K108) was also the most hydrophilic point of SAA1 as calculated by the method of Kyte and Doolittle [71]. Thus, ICU-Sepsis showed cleavage on the $\mathrm{COOH}$ side of the previously established Cystatin $\mathrm{C}$ binding site [72] and elsewhere more frequently than any other disease or control treatment. Moreover, the D/PNHFRPAGLPEKY peptide was not observed in ice cold normal samples shown herein or in similar samples warmed to room temperature [39] and so $\mathrm{COOH}$ cleavage of SAA1 does not apparently result from poor sample handling. Furthermore, SAA1 cleavages on the NH2 terminal side of the Cystatin binding site were observed in ICU-Sepsis but not ICU Control. The sepsis-specific peptides apparently result from the ex vivo action of proteases from septic patients that are secreted or activated as a part of the host response to 
infection. It should be possible to specifically compare and confirm the disease specific expression of peptides and/or parent proteins by automatic targeted proteomics [40] after extraction of peptides [43], or after collection of the parent protein over the best partition chromatography resin followed by exogenous tryptic digestion [41] to test the discovery on a larger set of samples. For example, C4B peptides discovered by random and independent sampling were shown to be a marker of sample degradation by automatic targeted assays [39, 40,65]. Automatic targeted analysis of peptides was an independent analysis that provided relative quantification to rapidly confirm the potential utility of $\mathrm{C} 4 \mathrm{~B}$ peptide as a marker of sample degradation [40]. Subsequently, the best performing peptides may be absolutely quantified by external or internalisotopic standards to provide absolute quantification. Thus, by monitoring the processing of SAA1 in EDTA plasma by LC-ESI-MS/MS it might be possible to detect and resolve ICU-Sepsis patients from the background population of ICU.

\section{Conclusion}

It was possible to discover peptides and/or proteins that showed variation specific to sepsis versus other diseases, or normal plasma samples, from many institutions using simple, disposable sample preparation, common benchtop instrumentation, and generic computation. The results of the step-wise organic extraction of peptides [42] provided for the enrichment of endogenous tryptic peptides with high signal to noise for random sampling [40] across disease and normal treatments. A large amount of MS and MS/MS spectra data from multiple diseases, controls and institutions may be collected by random and independent sampling with a set of robust and sensitive linear quadrupole ion traps and fit to peptides using X!TANDEM or SEQUEST and stored, related and statistically analyzed in 64 bit SQL Server/R. Analyzing the resulting database by Chi square and ANOVA with SQL Server R identified proteins and peptides specific to ICU-Sepsis versus other diseases. The LC-ESIMS/MS of plasma endogenous tryptic peptides identified many blood proteins and/or peptides elevated in ICUSepsis versus ICU Control that were previously associated with the innate immune response. Cleavage of the SAA1 protein to release peptides from the $\mathrm{COOH}$ terminal and elsewhere was more frequent in sepsis compared to all other diseases and controls. SAA1 peptides discovered by random and independent sampling of test samples might be confirmed by automatic targeted LCESI-MS/MS [39, 40, 65] from a larger cohort of independent samples.

\section{Supplementary information}

Supplementary information accompanies this paper at https://doi. org/10.1186/s12014-020-09288-5.

Additional file 1: Table S1. The tryptic peptides with Chi square FDR q-values.

Additional file 2: Table S2. The tryptic phosphopeptides with Chi square FDR q-values.

Additional file 3: Table S3. Gene Ontology distributions of the Chi square data from corrected frequency that differ by at least 10 observations and a Chi square $x^{2}>9$. Network statistics: number of nodes, 484; number of edges, 1147; average node degree, 4.74; avg. local clustering coefficient, 0.324; expected number of edges, 850; PPI enrichment $\mathrm{p}$-value: $<1.0 \mathrm{e}-16$.

\section{Abbreviations}

TRYP: Fully tryptic; TRYP STYP: Fully tryptic and/or S, T or Y tryptic phosphopeptide; ICU: Intensive Care Unit.

\section{Acknowledgements}

We thank Dr. R.A. Phillips for his long running support for this program of research, his aid in obtaining human EDTA plasma from the Ontario Tumor Bank, which is funded by the Ontario Institute for Cancer Research, and his help and opinions in the preparation of the manuscript.

\section{Authors' contributions}

TT prepared samples and performed LC-ESI-MS/MS analysis. CCS planned the study, provided sepsis samples and wrote the manuscript. ASS planned the study and wrote a grant in support of the study. JCM planned the study, provided sepsis samples. AR planned the study and devised the peptide collection and sample injection method. PB performed the X!TANDEM and SEQUEST correlations and created the SQL Server database. JGM planned the study, wrote grants in support of the study, performed the R statistical analysis and wrote the manuscript. All authors read and approved the final manuscript.

\section{Funding}

Funding to develop the SQL SERVER-R computation platform, and to sample the breast and ovarian cancer samples, provided by the Ontario Institute of Cancer Research through the Ontario Cancer Biomarker Network to KWS, EPD, and JGM. The funding to create the reference control samples and sample the AD and MS plasma and controls was from Fonds National de la Recherche, through Luxembourg Institute of Health LIH (formerly CRP Sante) and the Integrated Biobank of Luxembourg (IBBL) to JGM. The heart attack results were collected using funding from the Heart and Stroke Foundation of Ontario and Canada to JGM. Funding for wet lab and LC-ESI-MS/MS instruments and for sampling Sepsis was from the Natural Science and Engineering Research Council of Canada (NSERC) for the Discovery Grant and CRD Grant with YYZ Pharmatech to JGM.

Availability of data and materials

The raw data is provided in companion publication and its additional files.

Ethics approval and consent to participate

Human EDTA plasma samples were obtained under Ryerson Ethical Reviews Board Protocol REB 2015-207.

\section{Consent for publication}

No original figures or tables from any other publisher was reproduced in this publication.

\section{Competing interests}

The authors declare that they have no competing interests.

\section{Author details}

${ }^{1}$ Ryerson Analytical Biochemistry Laboratory (RABL), Department of Chemistry and Biology, Faculty of Science, Ryerson University, 350 Victoria St., Toronto, ON, Canada. ${ }^{2}$ St. Michael's Hospital, Keenan Research Centre for Biomedical Science, Toronto, Canada. ${ }^{3}$ St. Michael's Hospital, Keenan Chair in Medicine, University of Toronto, Toronto, Canada. ${ }^{4}$ International Biobank of Luxembourg 
(IBBL), Institute of Health (formerly CRP Sante Luxembourg), Dudelange, Luxembourg.

Received: 17 January 2020 Accepted: 15 June 2020

Published online: 02 July 2020

\section{References}

1. Ludwig KR, Hummon AB. Mass spectrometry for the discovery of biomarkers of sepsis. Mol BioSyst. 2017;13(4):648-64.

2. Assicot $M$, et al. High serum procalcitonin concentrations in patients with sepsis and infection. Lancet. 1993;341(8844):515-8.

3. Garcia-Obregon S, et al. Identification of a panel of serum protein markers in early stage of sepsis and its validation in a cohort of patients. J Microbiol Immunol Infect. 2018;51(4):465-72.

4. Ren $Y$, et al. The alterations of mouse plasma proteins during septic development. J Proteome Res. 2007;6(7):2812-21.

5. Jiao J, et al. Identification of potential biomarkers by serum proteomics analysis in rats with sepsis. Shock. 2014;42(1):75-81.

6. Cuello F, et al. Redox state of pentraxin 3 as a novel biomarker for resolution of inflammation and survival in sepsis. Mol Cell Proteomics. 2014;13(10):2545-57.

7. Qian WJ, et al. Quantitative proteome analysis of human plasma following in vivo lipopolysaccharide administration using 160/180 labeling and the accurate mass and time tag approach. Mol Cell Proteomics. 2005;4(5):700-9.

8. Shen Z, et al. Sepsis plasma protein profiling with immunodepletion, three-dimensional liquid chromatography tandem mass spectrometry, and spectrum counting. J Proteome Res. 2006;5(11):3154-60.

9. DeCoux A, et al. Plasma glycoproteomics reveals sepsis outcomes linked to distinct proteins in common pathways. Crit Care Med. 2015:43(10):2049-58.

10. Cao Z, et al. Proteomics reveals age-related differences in the host immune response to sepsis. J Proteome Res. 2014;13(2):422-32.

11. Punyadeera C, et al. A biomarker panel to discriminate between systemic inflammatory response syndrome and sepsis and sepsis severity. J Emerg Trauma Shock. 2010;3(1):26-35.

12. Andaluz-Ojeda $\mathrm{D}$, et al. A combined score of pro- and anti-inflammatory interleukins improves mortality prediction in severe sepsis. Cytokine. 2012;57(3):332-6.

13. Yang $\mathrm{Y}$, et al. Combination of $\mathrm{C}$-reactive protein, procalcitonin and sepsisrelated organ failure score for the diagnosis of sepsis in critical patients. Ann Intensive Care. 2016;6(1):51.

14. Gibot S, et al. Combination biomarkers to diagnose sepsis in the critically ill patient. Am J Respir Crit Care Med. 2012;186(1):65-71.

15. Liu J, Li J, Deng X. Proteomic analysis of differential protein expression in platelets of septic patients. Mol Biol Rep. 2014;41(5):3179-85.

16. Alder MN, et al. Olfactomedin-4 is a candidate marker for a pathogenic neutrophil subset in septic shock. Crit Care Med. 2017;45(4):e426-32.

17. Malmstrom E, et al. Targeted mass spectrometry analysis of neutrophilderived proteins released during sepsis progression. Thromb Haemost. 2014;112(6):1230-43.

18. Martin CM, et al. A prospective, observational registry of patients with severe sepsis: the Canadian Sepsis Treatment and Response Registry. Crit Care Med. 2009;37(1):81-8.

19. Heyland DK, et al. Identifying critically ill patients who benefit the most from nutrition therapy: the development and initial validation of a novel risk assessment tool. Crit Care. 2011;15(6):R268.

20. Hayashi $\mathrm{N}$, et al. Multiple biomarkers of sepsis identified by novel timelapse proteomics of patient serum. PLoS ONE. 2019;14(9):e0222403.

21. Pimienta $G$, et al. Plasma proteome signature of sepsis: a functionally connected protein network. Proteomics. 2019;19(5):e1800389.

22. Tiss A, et al. A well-characterised peak identification list of MALDI MS profile peaks for human blood serum. Proteomics. 2010;10(18):3388-92.

23. Oleschuk RD, et al. Characterization of plasma proteins adsorbed onto biomaterials. By MALDI-TOFMS. Biomaterials. 2000;21(16):1701-10.

24. Tammen $\mathrm{H}$, et al. Detection of low-molecular-mass plasma peptides in the cavernous and systemic blood of healthy men during penile flaccidity and rigidity - an experimental approach using the novel differential peptide display technology. Urology. 2002;59(5):784-9.
25. Ardekani AM, Liotta LA, Petricoin EF 3rd. Clinical potential of proteomics in the diagnosis of ovarian cancer. Expert Rev Mol Diagn. 2002;2(4):312-20.

26. Petricoin EF, et al. Use of proteomic patterns in serum to identify ovarian cancer. Lancet. 2002;359(9306):572-7.

27. Villanueva J, et al. Differential exoprotease activities confer tumor-specific serum peptidome patterns. J Clin Invest. 2006;116(1):271-84.

28. Villanueva J, et al. Serum peptidome patterns that distinguish metastatic thyroid carcinoma from cancer-free controls are unbiased by gender and age. Mol Cell Proteomics. 2006;5(10):1840-52.

29. Villanueva J, et al. A sequence-specific exopeptidase activity test (SSEAT) for "functional" biomarker discovery. Mol Cell Proteomics. 2008;7(3):509-18.

30. Timms JF, et al. Peptides generated ex vivo from serum proteins by tumor-specific exopeptidases are not useful biomarkers in ovarian cancer. Clin Chem. 2010;56(2):262-71.

31. Bowden P, et al. Quantitative statistical analysis of standard and human blood proteins from liquid chromatography, electrospray ionization, and tandem mass spectrometry. J Proteome Res. 2012;11:2032-47.

32. Marshall J, et al. Processing of serum proteins underlies the mass spectral fingerprinting of myocardial infarction. J Proteome Res. 2003;2:361-72.

33. Eckel-Passow JE, et al. An insight into high-resolution mass-spectrometry data. Biostatistics. 2009;10(3):481-500.

34. Baggerly KA, et al. A comprehensive approach to the analysis of matrixassisted laser desorption/ionization-time of flight proteomics spectra from serum samples. Proteomics. 2003;3(9):1667-72.

35. Marshall J, et al. Human serum proteins preseparated by electrophoresis or chromatography followed by tandem mass spectrometry. J Proteome Res. 2004;3(3):364-82.

36. Bowden P, Beavis R, Marshall J. Tandem mass spectrometry of human tryptic blood peptides calculated by a statistical algorithm and captured by a relational database with exploration by a general statistical analysis system. J Proteomics. 2009;73:103-11.

37. Florentinus AK, et al. Identification and quantification of peptides and proteins secreted from prostate epithelial cells by unbiased liquid chromatography tandem mass spectrometry using goodness of fit and analysis of variance. J Proteomics. 2012;75:1303-17.

38. Florentinus AK, et al. The Fc receptor-cytoskeleton complex from human neutrophils. J Proteomics. 2011;75:450-68.

39. Dufresne J, et al. Random and independent sampling of endogenous tryptic peptides from normal human EDTA plasma by liquid chromatography micro electrospray ionization and tandem mass spectrometry. Clin Proteomics. 2017;14:41.

40. Dufresne J, et al. Freeze-dried plasma proteins are stable at room temperature for at least 1 year. Clin Proteomics. 2017;14:35.

41. Tucholska $\mathrm{M}$, et al. Human serum proteins fractionated by preparative partition chromatography prior to LC-ESI-MS/MS. J Proteome Res. 2009;8:1143-55.

42. Dufresne J, et al. A method for the extraction of the endogenous tryptic peptides (peptidome) from human EDTA plasma. Anal Biochem. 2018;549:188-96

43. Tucholska M, et al. The endogenous peptides of normal human serum extracted from the acetonitrile-insoluble precipitate using modified aqueous buffer with analysis by LC-ESI-Paul ion trap and Qq-TOF. J Proteomics. 2010;73(6):1254-69.

44. Tucholska M, et al. Endogenous peptides from biophysical and biochemical fractionation of serum analyzed by matrix-assisted laser desorption/ ionization and electrospray ionization hybrid quadrupole time-of-flight. Anal Biochem. 2007;370:228-45.

45. Williams D, et al. Precipitation and selective extraction of human serum endogenous peptides with analysis by quadrupole time-of-flight mass spectrometry reveals posttranslational modifications and low-abundance peptides. Anal Bioanal Chem. 2010;396:1223-47.

46. Zhu P, et al. Mass spectrometry of peptides and proteins from human blood. Mass Spectrom Rev. 2011;30(5):685-732.

47. Declan Williams PZ, Bowden P, Stacey C, McDonell M, Kowalski P, Kowalski JM, Evans K, Diamandis EP, Michael Siu KW, Marshall J. Comparison of methods to examine the endogenous peptides of fetal calf serum clinical proteomics. Clin Proteomics. 2007;2(1):67-89. 
48. Chertov $\mathrm{O}$, et al. Organic solvent extraction of proteins and peptides from serum as an effective sample preparation for detection and identification of biomarkers by mass spectrometry. Proteomics. 2004;4(4):1 195-203.

49. Tirumalai RS, et al. Characterization of the low molecular weight human serum proteome. Mol Cell Proteomics. 2003;2(10):1096-103.

50. Pieper $\mathrm{R}$, et al. The human serum proteome: display of nearly 3700 chromatographically separated protein spots on two-dimensional electrophoresis gels and identification of 325 distinct proteins. Proteomics. 2003;3(7):1345-64.

51. Patterson SD. Data analysis-the Achilles heel of proteomics. Nat Biotechnol. 2003;21(3):221-2.

52. Craig R, Beavis RC. TANDEM: matching proteins with tandem mass spectra. Bioinformatics. 2004;20(9):1466-7.

53. Eng JK, McCormack AL, Yates JR. An approach to correlate tandem mass spectral data of peptides with amino acid sequences in a protein database. J Am Soc Mass Spectrom. 1994;5(11):976-89.

54. Dufresne J, et al. Re-evaluation of the rabbit myosin protein standard used to create the empirical statistical model for decoy library searching. Anal Biochem. 2018;560:39-49.

55. Zhu P, et al. Chi square comparison of tryptic peptide-to-protein distributions of tandem mass spectrometry from blood with those of random expectation. Anal Biochem. 2011;409(2):189-94.

56. Zhu P, et al. Peptide-to-protein distribution versus a competition for significance to estimate error rate in blood protein identification. Anal Biochem. 2011;411:241-53.

57. Benjamini $Y$, Hochberg Y. Controlling false discovery rate: a practical approach to multiple testing. J R Stat Soc. 1995;57(1):289-300.

58. Dufresne J, et al. The plasma peptides of ovarian cancer. Clin Proteomics. 2018:15:41.

59. Dufresne J, et al. The plasma peptidome. Clin. Proteomics. 2018;15:39.

60. Krokhin OV, Ens W, Standing KG. MALDI QqTOF MS combined with off-line HPLC for characterization of protein primary structure and posttranslational modifications. J Biomol Tech. 2005;16(4):429-40.

61. Schwartz JC, Senko MW, Syka JE. A two-dimensional quadrupole ion trap mass spectrometer. J Am Soc Mass Spectrom. 2002;13(6):659-69.
62. Yates JR 3rd, et al. Method to correlate tandem mass spectra of modified peptides to amino acid sequences in the protein database. Anal Chem. 1995;67(8):1426-36.

63. Bowden $\mathrm{P}$, et al. Meta sequence analysis of human blood peptides and their parent proteins. J Proteomics. 2010;73:1163-75.

64. Chick JM, et al. A mass-tolerant database search identifies a large proportion of unassigned spectra in shotgun proteomics as modified peptides. Nat Biotechnol. 2015;33(7):743-9.

65. Dufresne J, et al. The proteins cleaved by endogenous tryptic proteases in normal EDTA plasma by C18 collection of peptides for liquid chromatography micro electrospray ionization and tandem mass spectrometry. Clin Proteomics. 2017;14:39.

66. Thavarajah T. et al. Re-evaluation of the 18 non-human protein standards used to create the Empirical Statistical Model for Decoy Library Searching. Anal Biochem. 2020:113680.

67. Howard JC, et al. OxLDL receptor chromatography from live human U937 cells identifies SYK(L) that regulates phagocytosis of oxLDL. Anal Biochem. 2016;513:7-20.

68. Ruiz Martin G, et al. Plasma fibronectin as a marker of sepsis. Int J Infect Dis. 2004:8(4):236-43.

69. Balduyck M, et al. Inflammation-induced systemic proteolysis of interalpha-inhibitor in plasma from patients with sepsis. J Lab Clin Med. 2000;135(2):188-98.

70. Whitin JC, et al. A novel truncated form of serum amyloid A in Kawasaki disease. PLOS ONE. 2016:11(6):e0157024

71. Kyte J, Doolittle RF. A simple method for displaying the hydropathic character of a protein. J Mol Biol. 1982;157(1):105-32.

72. Spodzieja $M$, et al. Interaction of serum amyloid $A$ with human cystatin C-identification of binding sites. J Mol Recognit. 2012;25(10):513-24.

\section{Publisher's Note}

Springer Nature remains neutral with regard to jurisdictional claims in published maps and institutional affiliations.
Ready to submit your research? Choose BMC and benefit from:

- fast, convenient online submission

- thorough peer review by experienced researchers in your field

- rapid publication on acceptance

- support for research data, including large and complex data types

- gold Open Access which fosters wider collaboration and increased citations

- maximum visibility for your research: over $100 \mathrm{M}$ website views per year

At BMC, research is always in progress.

Learn more biomedcentral.com/submissions 